\title{
A Property Perceived Service Quality Evaluation Method for Public Building Based on Multi-Source Heterogeneous Information Fusion
}

wenjin zuo ( $\sim$ z2019108@shufe-zj.edu.cn )

Shanghai University of Finance and Economics Zhejiang College https://orcid.org/0000-0003-14114730

Lijun Liu

Shanghai University of Finance and Economics Zhejiang College

Xiaogang He

Shanghai University of Finance and Economics

Xingxian Zhang

Tongling University

Shouzhen Zeng

Ningbo University

\section{Research Article}

Keywords: Multi-source heterogeneous information, Multi-objective LINMAP model, Property perceived service quality evaluation, Public building

Posted Date: October 20th, 2021

DOl: https://doi.org/10.21203/rs.3.rs-906206/v1

License: (c) (1) This work is licensed under a Creative Commons Attribution 4.0 International License.

Read Full License 


\title{
A property perceived service quality evaluation method for public building based on multi-source heterogeneous information fusion
}

\author{
Wenjin Zuo ${ }^{1} \cdot$ Lijun Liu $^{1} \bullet$ Xiaogang $\mathrm{He}^{2} \cdot$ Xingxian Zhang $^{3} \bullet$ Shouzhen Zeng $^{4}$
}

\begin{abstract}
The basic information of property perceived service quality (PPSQ) evaluation for public building has the characteristics of multi-source heterogeneity, which challenges the traditional perceived service quality evaluation methods. Based on the classical linear programming technique for multidimensional analysis of preference (LINMAP), a multi-objective LINMAP model is constructed and a new PPSQ evaluation method is proposed to solve such problems. Constructing the multi-objective LINMAP model is the core of constructing the new PPSQ evaluation method. The construction idea of the multi-objective LINMAP model is as follows: First, the multi-source heterogeneous evaluation information is normalized based on the TOPSIS idea. Then, the LINMAP model is extended by using the objective function which is constructed with the minimum variance between the multi-source evaluation information. Finally, the source weight and index weight are determined by the above model, the comprehensive distance of each property service project is calculated, and the best choice of property service project is found. The case study verifies the feasibility and effectiveness of the multi-objective LINMAP model, but also reflects the new requirement of comprehensively and objectively evaluates PPSQ for public building.
\end{abstract}

Key words Multi-source heterogeneous information $•$ Multi-objective LINMAP model $•$ Property perceived service quality evaluation $\cdot$ Public building

\section{Introduction}

Public buildings are buildings where people carry out various public activities. Public buildings generally include scientific buildings, educational buildings, cultural buildings and health buildings, etc

Wenjin Zuo

z2012184@shufe-zj.edu.cn

1 Zhejiang College, Shanghai University of Finance and Economics, Jinhua 321013, China

2 Business of College, Shanghai University of Finance and Economics, Shanghai 200083, China

3 School of Architecture and Engineering, Tongling University, Tongling 244061, China

4 Business School, Ningbo University, Ningbo 315021, China 
(Wei et al. 2009). Property perceived service quality (PPSQ) refers to people's actual perceived level of property service provided by property service enterprise. PPSQ evaluation for public buildings involves the interests of various parties such as property service enterprise, regulatory agency and government, and the evaluation results have a wide range of social influences (Zuo et al. 2020). Scientific evaluation of PPSQ is an important means to improve the management ability and service quality of public buildings.

PPSQ evaluation for public buildings is usually characteristics by multiple evaluation subjects, complex information types and scattered information sources, that is, there is multi-source heterogeneity of evaluation information. What is multi-source heterogeneity? Multi-source information is also known as multi-sensor information, where the sensor refers to the equipment in the physical sense, but also refers to the human perception system. Heterogeneous information refers to the different types of information used by the evaluators in the practice of PPSQ evaluation. (Xu et al. 2018) Multi-source heterogeneous information fusion can improve information credibility and reduce information acquisition cost. In the PPSQ evaluation of residential buildings, the evaluation subject type is single and its information structure is relatively simple (Zuo et al. 2019). The linear programming technique for multidimensional analysis of preference (LINMAP) has the basic performance of heterogeneous information processing (Srinivasan and Shocker 1973). There are some the extended LINMAP and their application in PPSQ (Zuo et al. 2019; Zuo et al. 2020; Zuo et al. 2021). However, the PPSQ evaluation method based on multi-source heterogeneous information fusion has not been solved yet, the LINMAP model needs to be extended further.

To sum up, how to evaluate PPSQ for public buildings based on multi-source heterogeneous information is the basic problem of this paper. First of all, it is very important to determine the information source, and the correlation between the evaluation data from an information source and its evaluation results is the key to determining the information source. Secondly, heterogeneous data standardization should take into account the scientificity of basic data processing and the adaptability of the LINMAP model simultaneously. And last but not least, it is necessary to construct a multi-objective LINMAP model, so as to evaluate PPSQ for public buildings comprehensively and objectively. The key innovation of this paper lies in the model and method. In brief, a multi-objective LINMAP model is constructed and a multi-source heterogeneous evaluation method is proposed.

The other sections of this paper are organized as follows: In Section 2, the literatures on PPSQ evaluation and LINMAP model are briefly reviewed. In Section 3, the relevant mathematical symbols, 
multi-index and multi-scale (MIMS) information structure and its generalized form are introduced. In Section 4, the basic principles of evaluation method based on multi-source heterogeneous information are introduced. In Section 5, a case of PPSQ evaluation for public building by the proposed method is analyzed. In Section 6, the PPSQ is analyzed according to the results of information source weight, evaluation index weight and comprehensive ranking order. Finally, the advantages of the proposed method and their future research directions are summarized in Section 7.

\section{Literature review}

\subsection{Perceived service quality and PPSQ evaluation}

Since Gronroos (1983) first proposed the concept of perceived service quality, the evaluation methods of perceived service quality proposed by scholars include SERVQUAL (Berry et al. 1988), hierarchical model (Kao and Lin, 2016), fuzzy set quality cost analysis (Miranda et al. 2017), sentiment analysis and topic modeling (Lee and Yu, 2018), IVWMM (Liu and Zuo, 2019), DEMATEL (Wu et al. 2020) etc. The application of perceived service quality evaluation method covers the fields of IPTV service (Bruzgiene et al. 2013), staff satisfaction (Hung et al. 2013), marketing (Ramanathan and Karpuzcu, 2011; Knecht-Tarczewska, 2013), tourism (Jomnonkwao and Ratanavaraha, 2016; Liu and Zuo, 2019) and hospital service (Yucesan and Gul 2020). In existing research on perceived service quality evaluation, the evaluation subject is limited to customers, the information source is single, the information structure is simple, and the evaluation method is mainly the econometric analysis method based on SERVQUAL model.

PPSQ evaluation for public buildings mainly includes three elements: evaluation subject, information type and information source. The management mode of public buildings is changing from the traditional government decision-making to the collaborative decision-making with the participation of government, regulatory agency, experts and general publics (Xie and Yang, 2012), and the function of the government is executed by the regulatory agency in the practice of PPSQ evaluation for public building. Therefore, this paper determines that the evaluators of PPSQ evaluation for public buildings are regulatory agencies, invited experts and general publics. The functions of the management agency should be performed by the relevant functional departments of the property service enterprise. The invited experts are external professionals with relevant professional and practical experience. The general publics are the visitors of all public buildings. The diversity of evaluators usually leads to the difference of evaluation information types, which may 
include real numbers, interval numbers, fuzzy numbers and linguistic values (Yu et al. 2018). In the practice of PPSQ evaluation, the evaluation information sources are usually on-site questionnaire and telephone survey. With the development of the internet era, the importance of online information consumption has been highlighted, and its impact on the society is mainly reflected in the "plus and minus" two sides (Zhang, 2018). The most representative form of the growing influence of the Web is online review, which refers to peer-generated product evaluations posted on company or third party websites (Mudambi and Schuff, 2010). In a word, the basic data collection of PPSQ for public building is much more complex, and the existing evaluation methods cannot solve the problems faced by PPSQ evaluation for public building.

\subsection{The LINMAP model extension and its application}

In the traditional decision theory research, the linear programming technique for multi-dimensional analysis of preference (LINMAP) is an optimization method that can simultaneously process the overall preference information and the itemized evaluation information of the decision makers for the decision objects (Srinivasan and Shocker, 1973). The basic principle of the LINMAP model is as follows: First, a set of compromise values closest to the positive ideal point are generated by pairwise comparison between different alternatives. Then, the minimum inconsistency (or maximum consistency) is taken as the objective function, the relationship between consistency and inconsistency is taken as the constraint condition, and the linear programming model is constructed. Finally, the model is solved to determine the information source weight, index weight and the ranking order of all alternatives (Wan and Li, 2013; Zuo et al. 2019).

Scholars have successively applied the LINMAP model to process fuzzy number (Wan and Li, 2013), interval type-2 fuzzy number (Qin et al. 2017), probabilistic language (Liao et al. 2017), hybrid data (Wan et al. 2020) and dynamic uncertain information (Zuo et al. 2020), etc. The multi-source evaluation information usually has the characteristics of heterogeneity. Although the LINMAP model has the basic performance to process heterogeneous information, there is no relevant research on multi-source information fusion. Therefore, it is necessary to further improve the LINMAP model to meet the requirements of multi-source heterogeneous information fusion.

\section{Preliminaries}

Let $F=\left\{F_{1}, F_{2}, \ldots, F_{m}\right\}$ be the set of $m$ alternatives, where $F_{i}(i=1,2, \ldots, m)$ is the $i$ th alternative. Let $S=\left(s^{1}, s^{2}, \ldots, s^{q}\right)$ be the weight vector of $q$ information sources, where $s^{t}$ is the $t$ th information source, 
$\sum_{t=1}^{q} s^{t}=1, s^{t} \geq 0 \quad(t=1,2, \ldots, q)$. Let $A^{t}=\left\{A_{1}^{t}, A_{2}^{t}, \ldots, A_{n}^{t}\right\}$ be the set of $n$ indexes in the $t$ th information source, where $A_{j}^{t}(j=1,2, \ldots, n)$ is the $j$ th index in the $t$ th information source. Let $\omega^{t}=\left(\omega_{1}^{t}, \omega_{2}^{t}, \ldots, \omega_{n}^{t}\right)$ be the weight of the index set $A^{t}$, where $\omega_{j}^{t}$ is the weight of the $j$ th index in the $t$ th information source, $\sum_{j=1}^{n} \omega_{j}^{t}=1, \omega_{j}^{t} \geq 0$. Let $B^{t}=\left\{B_{1}^{t}, B_{2}^{t}, \ldots, B_{n}^{t}\right\}$ be the set of scale set corresponding to the scale set $A^{t}$, where $B_{j}^{t}$ is the $j$ th scale set in the $t$ th information source. Let $B_{j}^{t}=\left\{b_{j 1}^{t}, b_{j 2}^{t}, \ldots, b_{j n_{j}^{t}}^{t}\right\}$ be the scale set corresponding to the scale set $A_{j}^{t}$, where $b_{j k}^{t}\left(k=1,2, \ldots, n_{j}^{t}\right)$ is the $k$ th scale in the scale set $B_{j}^{t}$, and $n_{j}^{t}$ is the number of the $j$ th scale in the $t$ th information source. The equidistant scale is used here. Let $E=\left(e_{i j}^{t}\right)$ be the decision making matrix of multi-attribute decision-making, where $e_{i j}^{t}$ is the evaluation value of the index $A_{j}^{t}$ corresponding to the alternative $F_{i}$ in the $t$ th information source. In addition, $\Omega=\left\{(u, v) \mid A_{u} \succeq A_{v}\right\}$ be the set of opinions of all experts think that the alternative $A_{u}$ not inferior to $A_{v}$, where $u, v \in\{1,2, \ldots, m\}$.

Given that the evaluation index of PPSQ for public building may be expressed by different types information, this paper assumes that the evaluation value of the same index of each information source has the same data type, and the data type of evaluation value of the same index in different information sources is not completely the same. In order to effectively process basic evaluation information, MIMS method is introduced here. If each index is evaluated by using different scales of the same scale set in the classical multi-attribute decision-making matrix, it is called the MIMS method (Zhang and Fan 2010). MIMS method is an effective information collection method, which can be process large scale evaluation information. As each index is evaluated by the same index set, the performance of MIMS method for heterogeneous information is limited. If there are multiple evaluation scale sets in the classical multi-attribute decision-making matrix, that is, the scale sets of different evaluation indexes are not identical, it is called the generalized MIMS decision-making (Zuo et al. 2020). Obviously, the MIMS decision-making is a special form of the generalized MIMS decision-making. The generalized MIMS evaluation information is shown in Table 1.

For the generalized MIMS evaluation information, $e_{i j k}^{t}$ denotes the number who using the scale value $b_{j k}^{t}$ to evaluate the index $A_{j}^{t}$ of the alternative $F_{i}$ in the $t$ th information source. The formula for converting 
the evaluation information in Table 1 into the decision matrix $E$ can be expressed as follows:

$$
e_{i j}^{t}=\sum_{k=1}^{n_{j}^{t}} b_{j k}^{t} e_{i j k}^{t}
$$

where $i=1,2, \ldots, m, j=1,2, \ldots, n, t=1,2, \ldots, q$.

Table 1 Generalized MIMS evaluation information

\begin{tabular}{ccccccccccccccc}
\hline$A^{t}$ & \multicolumn{1}{c}{$A_{1}^{t}$} & \multicolumn{1}{c}{$A_{2}^{t}$} & \multicolumn{3}{c}{} \\
\hline$B_{j}^{t}$ & $b_{11}^{t}$ & $b_{12}^{t}$ & $\ldots$ & $b_{1 n_{1}^{t}}^{t}$ & $b_{21}^{t}$ & $b_{22}^{t}$ & $\ldots$ & $b_{2 n_{2}^{t}}^{t}$ & $\ldots$ & $b_{n 1}^{t}$ & $b_{n 2}^{t}$ & $\ldots$ & $b_{n}^{t}$ \\
$F_{1}$ & $e_{111}^{t}$ & $e_{12}^{t}$ & $\ldots$ & $e_{11 n_{1}^{t}}^{t}$ & $e_{121}^{t}$ & $e_{122}^{t}$ & $\ldots$ & $e_{12 n_{2}^{t}}^{t}$ & $\ldots$ & $e_{1 n 1}^{t}$ & $e_{1 n 2}^{t}$ & $\ldots$ & $e_{1 n n_{n}^{t}}^{t}$ \\
$F_{2}$ & $e_{211}^{t}$ & $e_{212}^{t}$ & $\ldots$ & $e_{21 n_{1}^{t}}^{t}$ & $e_{221}^{t}$ & $e_{222}^{t}$ & $\ldots$ & $e_{22 n_{2}^{t}}^{t}$ & $\ldots$ & $e_{2 n 1}^{t}$ & $e_{2 n 2}^{t}$ & $\ldots$ & $e_{2 n n_{n}^{t}}^{t}$ \\
$\ldots$ & $\ldots$ & $\ldots$ & $\ldots$ & $\ldots$ & $\ldots$ & $\ldots$ & $\ldots$ & $\ldots$ & $\ldots$ & $\ldots$ & $\ldots$ & $\ldots$ & $\ldots$ \\
$F_{m}$ & $e_{m 11}^{t}$ & $e_{m 12}^{t}$ & $\ldots$ & $e_{m 1 n_{1}^{t}}^{t}$ & $e_{m 21}^{t}$ & $e_{m 22}^{t}$ & $\ldots$ & $e_{m 2 n_{2}^{t}}^{t}$ & $\ldots$ & $e_{m n 1}^{t}$ & $e_{m n 2}^{t}$ & $\ldots$ & $e_{m n n_{n}^{t}}^{t}$ \\
\hline
\end{tabular}

\section{Evaluation method based on multi-source heterogeneous information}

The basic principle of the evaluation method based on multi-source heterogeneous information includes evaluation information collection, data normalized processing and multi-objective LINMAP model construction, among which the multi-objective LINMAP model construction is the focus of the following elaboration.

\subsection{Multi-source heterogeneous evaluation information collection}

The selection of information sources mainly considers the importance of the evaluation information source. If the evaluation information from an information source has a great influence on the evaluation results, the information source should be selected. Otherwise, it should not be selected. The selection of information sources can be determined based on the information source weight. Therefore, the empirical analysis results can be used as the basis for selecting the information source. Due to the lack of relevant empirical research, we consulted three property management experts and determined three information sources: supervision records, online reviews and questionnaire survey. The supervision records are subject to the daily evaluation information of each functional department, and the online review and questionnaire survey are indirectly or directly evaluate by the visitors respectively. Although the evaluation information of online review and questionnaire survey is large scale evaluation data, the generalized MIMS method is used to process the evaluation information. The following describes the requirements of information collection in combination with the characteristics of different information sources.

(1) The supervision records are completed by functional departments of property service enterprise, and 
evaluation information comes from inspection records or professional evaluations of functional departments such as customer service, cleaning, safety, greening and facilities. Each functional department records the process of itemized property service with triangular fuzzy number, real number, hesitant fuzzy number, language value and interval value respectively. Among them, the evaluation value interval expressed in the form of triangular fuzzy number is $[0,10]$, the evaluation value interval expressed in the form of hesitating fuzzy number is $[0,10]$, the evaluation value interval expressed in the form of interval value is $[0,10]$, the evaluation value interval expressed in the form of real number is $[0$, 100], the evaluation value interval expressed in the form of language value is $\left[\mathrm{S}_{1}, \mathrm{~S}_{5}\right]$, the evaluation scale interval expressed in the form of online review is $\{1,2,3\}$, and the evaluation scale interval expressed in the form of MIMS information is $\{1,2,3,4,5\}$. All the elements in the evaluation interval from the smallest to the largest represent from the worst to the best.

(2) Online reviews come from WeChat APPs, official websites and other network platforms related to the evaluation objects. The method of combining web crawler and manual processing is used to collect the evaluation information. Based on the characteristics of the research object, the original evaluation information adopts the structure of "degree adverbs + emotion words" by referring to the existing method (Wang et al. 2018; Bazeer Ahamed and Murugan, 2020). The degree adverbs are divided into two levels: $\mathrm{S}$ and $\mathrm{W}$, and the emotion words are divided into two levels: $\mathrm{P}$ and $\mathrm{N}$. The online review is collected by three-level marking method, which is divided into three levels: first-level (degree adverb $\mathrm{S}+$ emotion word $\mathrm{N}$ ), second-level (degree adverb $\mathrm{W}+$ emotion word $\mathrm{N}$, degree adverb $\mathrm{W}+$ emotion word $\mathrm{P}$ ) and third-level (degree adverb $\mathrm{S}+$ emotion word P), and assign the scores 1, 2 and 3 in turn.

(3) Questionnaire survey is a basic data collection method of PPSQ evaluation, which is the most widely used in the practice of property service evaluation. The main content of the questionnaire is to ask visitors to evaluate PPSQ of each index. The 5-degree labeling method is the most commonly used method for quality evaluation. The evaluation value usually adopts 5-degree labeling method, which is denoted as very poor, poor, average, good and very good, and assign the scores 1, 2, 3, 4 and 5 in turn. In other cases, the labeling method of 7-degree, 9-degree and others numbers can be used, and their scores can be changed accordingly. In order to improve the accuracy of the evaluation results, the evaluators should be familiar with the property service environment of four public buildings at the same time. In some realistic evaluation situations, it is difficult to do as the above completely. If the restriction is 
relaxed, the optional evaluator is required to be familiar with all attributes of the two evaluation objects at least simultaneously and make an objective and complete evaluation.

\subsection{Multi-source heterogeneous evaluation information standardization}

The consistency and inconsistency of the LINMAP model are based on the distance between the evaluation value of each alternative and its ideal point. To ensure that multi-source heterogeneous information processing meets the inherent requirements of the LINMAP model, this paper uses TOPSIS method for reference to carry out standardized processing of multi-source heterogeneous information.

In the evaluation matrix, let $e_{j}^{t+}$ and $e_{j}^{t-}$ be positive and negative ideal points respectively, let $D\left(e_{i j}^{t}, e_{j}^{t+}\right)$ be the distance between the evaluation value of any alternative and its positive ideal point, and $D\left(e_{i j}^{t}, e_{j}^{t-}\right)$ be the distance between the evaluation value of any alternative and its negative ideal point. The Euclidean distance square value is adopted in this paper. Let $Z=\left(z_{i j}^{t}\right)$ be the standardized matrix. The idea of determining the ideal point is as follows: when the evaluation value of the same index in an information source is a benefit variable, $e_{j}^{t+}$ and $e_{j}^{t-}$ are the maximum and minimum evaluation values of the $j$ th index of the $t$ th information source respectively; When the evaluation value of the same index in an information source is a cost type variable, $e_{j}^{t+}$ and $e_{j}^{t-}$ are the minimum and maximum evaluation values of the $j$ th index of the $t$ th information source respectively.

For the evaluation value in the original evaluation matrix, the processing method is designed based on the assumption that all indexes are all benefit variables. The basic formula for the standardized processing of multi-source heterogeneous evaluation information of benefit index is as follows:

$$
z_{i j}^{t}=\frac{D\left(e_{i j}^{t}, e_{j}^{t-}\right)}{D\left(e_{i j}^{t}, e_{j}^{t-}\right)+D\left(e_{i j}^{t}, e_{j}^{t+}\right)}
$$

where $D\left(e_{i j}^{t}, e_{j}^{t-}\right)=\left(e_{i j}^{t}-e_{j}^{t-}\right)^{2}$ and $D\left(e_{i j}^{t}, e_{j}^{t+}\right)=\left(e_{i j}^{t}-e_{j}^{t+}\right)^{2}$.

For any real number $e_{i j}^{t}$ in the original evaluation matrix, the positive and negative ideal points are calculated by $e_{j}^{t+}=\max _{i=1}^{m} e_{i j}^{t}$ and $e_{j}^{t-}=\min _{i=1}^{m} e_{i j}^{t}$ respectively. So there are $D\left(e_{i j}^{t}, e_{j}^{t+}\right)=\left(e_{i j}^{t}-\max _{i=1}^{m} e_{i j}^{t}\right)^{2}$ and $D\left(e_{i j}^{t}, e_{j}^{t-}\right)=\left(e_{i j}^{t}-\min _{i=1}^{m} e_{i j}^{t}\right)^{2}$. Therefore, the standardized processing formula of real number index is as follows:

$$
z_{i j}^{t}=\frac{\left(e_{i j}^{t}-\min _{i=1}^{m} e_{i j}^{t}\right)^{2}}{\left(e_{i j}^{t}-\min _{i=1}^{m} e_{i j}^{t}\right)^{2}+\left(e_{i j}^{t}-\max _{i=1}^{m} e_{i j}^{t}\right)^{2}}
$$

For any interval number $\left[\underline{e}_{i j}^{t}, \bar{e}_{i j}^{t}\right]$ in the original evaluation matrix, the positive and negative ideal points are calculated by $e_{j}^{t+}=\left[\max _{i=1}^{m} \underline{e}_{i j}^{t}, \max _{i=1}^{m} \bar{e}_{i j}^{t}\right]$ and $e_{j}^{t-}=\left[\min _{i=1}^{m} e_{i j}^{t}, \min _{i=1}^{m} \bar{e}_{i j}^{t}\right]$ respectively. So there are 
$D\left(e_{i j}^{t}, e_{j}^{t+}\right)=1 / 2\left[\left(\underline{e}_{i j}^{t}-\max _{i=1}^{m} \underline{e}_{i j}^{t}\right)^{2}+\left(\bar{e}_{i j}^{t}-\max _{i=1}^{m} \bar{e}_{i j}^{t}\right)^{2}\right]$ and $D\left(e_{i j}^{t}, e_{j}^{t-}\right)=1 / 2\left[\left(e_{i j}^{t}-\min _{i=1}^{m} \underline{e}_{i j}^{t}\right)^{2}+\left(\bar{e}_{i j}^{t}-\min _{i=1}^{m} \bar{e}_{i j}^{t}\right)^{2}\right]$.

Therefore, the standardized processing formula of the interval number index is as follows:

$$
z_{i j}^{t}=\frac{\sum_{e \in\{\underline{e}, \bar{e}\}}\left(e_{i j}^{t}-\min _{i=1}^{m} e_{i j}^{t}\right)^{2}}{\sum_{e \in\{\underline{e}, \bar{e}\}}\left(e_{i j}^{t}-m_{i=1}^{m} e_{i j}^{t}\right)^{2}+\sum_{e \in\{\underline{\underline{e}, e}\}}\left(e_{i j}^{t}-\max _{i=1}^{m} e_{i j}^{t}\right)^{2}}
$$

For any triangular fuzzy number $\left(e_{i j}^{t 1}, e_{i j}^{t 2}, e_{i j}^{t 3}\right)$ in the original evaluation matrix, the positive and negative ideal points are calculated by $e_{j}^{t+}=\left(\max _{i=1}^{m} e_{i j}^{t 1}, \max _{i=1}^{m} e_{i j}^{t 2}, \max _{i=1}^{m} e_{i j}^{t 3}\right)$ and $e_{j}^{t-}=\left(\min _{i=1}^{m} e_{i j}^{t 1}, \min _{i=1}^{m} e_{i j}^{t 2}, \min _{i=1}^{m} e_{i j}^{t 3}\right)$ respectively. So there are $D\left(e_{i j}^{t}, e_{j}^{t+}\right)=1 / 3 \sum_{x=1}^{3}\left(e_{i j}^{t x}-\max _{i=1}^{m} e_{i j}^{t x}\right)^{2}$ and $D\left(e_{i j}^{t}, e_{j}^{t-}\right)=1 / 3 \sum_{x=1}^{3}\left(e_{i j}^{t x}-\min _{i=1}^{m} e_{i j}^{t x}\right)^{2}$. Therefore, the standardized processing formula of triangular fuzzy number index is as follows:

$$
z_{i j}^{t}=\frac{\sum_{x=1}^{3}\left(e_{i j}^{t x}-\min _{i=1}^{m} e_{i j}^{t x}\right)^{2}}{\sum_{x=1}^{3}\left(e_{i j}^{t x}-\min _{i=1}^{m} e_{i j}^{t x}\right)^{2}+\sum_{x=1}^{3}\left(e_{i j}^{t x}-\max _{i=1}^{m} e_{i j}^{t x}\right)^{2}}
$$

Since the number of fuzzy elements of different hesitate fuzzy numbers may be different, some fuzzy elements added to the hesitating fuzzy number with a small number of fuzzy elements (Liao et al. 2014). The specific method of adding the fuzzy element is $e_{i j}^{t *}=\xi \min _{l=1}^{L} e_{i j}^{t l}+(1-\xi) \max _{l=1}^{L} e_{i j}^{t l}(l=1,2, \ldots, L, \xi \in[0,1])$. This paper determines $\xi=0.5$ according to the experience of decision makers. Assuming that all fuzzy elements in the hesitant fuzzy number are arranged in the order from small to large. For any hesitant fuzzy number $\left\{e_{i j}^{t 1}, e_{i j}^{t 2}, \ldots, e_{i j}^{t L}\right\}$ in the original evaluation matrix, the positive and negative ideal points are calculated by $e_{j}^{t+}=\left\{\max _{i=1}^{m} e_{i j}^{t 1}, \max _{i=1}^{m} e_{i j}^{t 2}, \ldots, \max _{i=1}^{m} e_{i j}^{t L}\right\}$ and $e_{j}^{t-}=\left\{\min _{i=1}^{m} e_{i j}^{t 1}, \min _{i=1}^{m} e_{i j}^{t 2}, \ldots, \min _{i=1}^{m} e_{i j}^{t L}\right\}$ respectively. So there are $D\left(e_{i j}^{t}, e_{j}^{t+}\right)=(1 / L) \sum_{x=1}^{L}\left(e_{i j}^{t x}-\max _{i=1}^{m} e_{i j}^{t x}\right)^{2}$ and $D\left(e_{i j}^{t}, e_{j}^{t-}\right)=(1 / L) \sum_{x=1}^{L}\left(e_{i j}^{t x}-\min _{i=1}^{m} e_{i j}^{t x}\right)^{2}$. Therefore, the standardized processing formula of hesitate fuzzy number index is as follows:

$$
z_{i j}^{t}=\frac{\sum_{x=1}^{L}\left(e_{i j}^{t x}-\min _{i=1}^{m} e_{i j}^{t x}\right)^{2}}{\sum_{x=1}^{L}\left(e_{i j}^{t x}-m_{i=1}^{m} e_{i j}^{t x}\right)^{2}+\sum_{x=1}^{L}\left(e_{i j}^{t x}-\max _{i=1}^{m} e_{i j}^{t x}\right)^{2}}
$$

For any language value $e_{i j}^{t}$ in the original evaluation matrix, the positive and negative ideal points are calculated by $e_{j}^{t+}=\max _{i=1}^{m}\left(\Delta^{-1} e_{i j}^{t}\right) \quad$ and $\quad e_{j}^{t-}=\min _{i=1}^{m}\left(\Delta^{-1} e_{i j}^{t}\right) \quad$ respectively. So there are $D\left(e_{i j}^{t}, e_{j}^{t+}\right)=\left(\left(\Delta^{-1} e_{i j}^{t}\right)-\max _{i=1}^{m}\left(\Delta^{-1} e_{i j}^{t}\right)\right)^{2}$ and $D\left(e_{i j}^{t}, e_{j}^{t-}\right)=\left(\left(\Delta^{-1} e_{i j}^{t}\right)-\min _{i=1}^{m}\left(\Delta^{-1} e_{i j}^{t}\right)\right)^{2}$. Therefore, the standardized processing formula of language value index is as follows:

$$
z_{i j}^{t}=\frac{\left(\left(\Delta^{-1} e_{i j}^{t}\right)-\min _{i=1}^{m}\left(\Delta^{-1} e_{i j}^{t}\right)\right)^{2}}{\left(\left(\Delta^{-1} e_{i j}^{t}\right)-\min _{i=1}^{m}\left(\Delta^{-1} e_{i j}^{t}\right)\right)^{2}+\left(\left(\Delta^{-1} e_{i j}^{t}\right)-\max _{i=1}^{m}\left(\Delta^{-1} e_{i j}^{t}\right)\right)^{2}}
$$

For the MIMS data $e_{i j k}^{t}$ in the original evaluation information, the total score of the evaluation value 
under the same information source, alternative and index is firstly calculated by Eq. (1). The positive and negative ideal points are calculated by $e_{j}^{t+}=\max _{i=1}^{m}\left(\sum_{k=1}^{n_{j}^{t}} b_{j k}^{t} e_{i j k}^{t}\right)$ and $e_{j}^{t-}=\min _{i=1}^{m}\left(\sum_{k=1}^{n_{j}^{t}} b_{j k}^{t} e_{i j k}^{t}\right)$ respectively.

There are $D\left(e_{i j}^{t}, e_{j}^{t+}\right)=\left(\sum_{k=1}^{n_{j}^{t}} b_{j k}^{t} e_{i j k}^{t}-\max _{i=1}^{m}\left(\sum_{k=1}^{n_{j}^{t}} b_{j k}^{t} e_{i j k}^{t}\right)\right)^{2}$ and $D\left(e_{i j}^{t}, e_{j}^{t-}\right)=\left(\sum_{k=1}^{n_{j}^{t}} b_{j k}^{t} e_{i j k}^{t}-\min _{i=1}^{m}\left(\sum_{k=1}^{n_{j}^{t}} b_{j k}^{t} e_{i j k}^{t}\right)\right)^{2}$. Therefore, the standardized processing formula of MIMS data can be expressed as follows:

$$
z_{i j}^{t}=\frac{\left(\sum_{k=1}^{n_{j}^{t}} b_{j k}^{t} e_{i j k}^{t}-\min _{i=1}^{m}\left(\sum_{k=1}^{n_{j}^{t}} b_{j k}^{t} e_{i j k}^{t}\right)\right)^{2}}{\left(\sum_{k=1}^{n_{j}^{t}} b_{j k}^{t} e_{i j k}^{t}-\min _{i=1}^{m}\left(\sum_{k=1}^{n_{j}^{t}} b_{j k}^{t} e_{i j k}^{t}\right)\right)^{2}+\left(\sum_{k=1}^{n_{j}^{t}} b_{j k}^{t} e_{i j k}^{t}-\max _{i=1}^{m}\left(\sum_{k=1}^{n_{j}^{t}} b_{j k}^{t} e_{i j k}^{t}\right)\right)^{2}}
$$

Eqs. (2) to (8) are used to standardize the multi-source heterogeneous data of the benefit type in the original evaluation matrix, so as to meet the data processing requirements of the LINMAP model.

If there are cost indexes in the original matrix, the formula for converting cost-type index into benefit-type index based on the above standardization results by referring to the method of Yu et al. (2018) can be expressed as follows:

$$
z_{i j}^{t^{\prime}}=1-z_{i j}^{t}
$$

\subsection{Construction of multi-objective LINMAP model}

The ideas of multi-objective LINMAP model are constructed as follows: First, the relationship of evaluation information between information sources is defined and the special objective function is constructed. Then, based on the standardized data from the above multi-source heterogeneous information, a multi-objective LINMAP model is constructed by using the classical LINMAP model. Finally, the multi-objective LINMAP model is transformed into a single-objective LINMAP model and the index weights are determined by solving the above model.

Since the evaluation objects of multi-source heterogeneous information are the same, the evaluation results of different information sources for the same evaluation object are theoretically consistent. In this paper, the minimum mean square error (MMSE) method is introduced to define the relationship of multi-source information.

Let $z_{i}^{t}$ be the comprehensive evaluation value of the $i$ th evaluation alternative in the $t$ th information source, the calculation formula is $z_{i}^{t}=\sum_{j=1}^{n} \omega_{j}^{t} z_{i j}^{t}$. Let $\sigma_{i}$ denotes MMSE of the comprehensive evaluation value of the $i$ th alternative, and $E$ be the square value of MMSE of all alternatives. The calculation formula can be expressed as follows:

$$
E=\sum_{i=1}^{m} \sigma_{i}=\sum_{i=1}^{m} \sqrt{\frac{1}{q} \sum_{t=1}^{q}\left(z_{i}^{t}-\bar{z}_{i}^{*}\right)^{2}}
$$

where $\bar{z}_{i}^{*}=\sum_{t=1}^{q}\left(s^{t} \sum_{j=1}^{n} \omega_{j}^{t} z_{i j}^{t}\right)$.

Therefore, the new model contains two objectives: minimum inconsistency in classical LINMAP model 
and MMSE of multi-source heterogeneous information, that is, the objective functions of the new model include $\min \{I C\}$ and $\min \{E\}$.

The consistency and inconsistency in LINMAP model are based on the compromise value, which is obtained by using TOPSIS method to compare different alternatives. Therefore, the next step is to determine the positive ideal point of the standardized matrix, and determine the weighted distance square value between the evaluation value of each alternative and its positive ideal point.

Because the above multi-source evaluation information belongs to the three-dimensional structure, its ideal points and evaluation values of each alternative constitute the matrix structure respectively. The positive ideal point is the maximum evaluation value of different alternatives in certain index of certain information source. Let $\left(z_{j}^{t+}\right)_{n \times q}$ be the positive ideal point of multi-source heterogeneous evaluation information. Let $P\left(F_{u}\right)$ and $P\left(F_{v}\right)$ be the evaluation values of the alternatives $F_{u}$ and $F_{v}$ respectively. The above matrices can be expressed as follows:

$$
\begin{gathered}
P\left(F_{u}\right)=\left(z_{u j}^{t}\right)_{n \times q} \\
P\left(F_{v}\right)=\left(z_{v j}^{t}\right)_{n \times q} \\
\left(z_{j}^{t+}\right)_{n \times q}=\left(\max _{i=1}^{m} z_{i j}^{t}\right)_{n \times q}
\end{gathered}
$$

Eq. (13) is suitable for the benefit index processing. For the cost index in the original matrix, Eq. (13) should be replaced as $\left(z_{i j}^{t+}\right)_{n \times q}=\left(\min _{i=1}^{m} z_{i j}^{t}\right)_{n \times q}$.

In the LINMAP model, experts provide a set of pairwise comparative preference relations between some alternatives according to their knowledge, experience and judgment. The preferences set can be denoted as $\Omega=\left\{(u, v) \mid F_{u} \succeq F_{v},(u, v=1,2, \ldots, m)\right\}$, where $F_{u} \succeq F_{v}$ denotes that experts think that the alternative $F_{u}$ is not inferior to the alternative $F_{v}$. The weighted Euclidean square distance is used to express the distance between the evaluation value of each alternative and its ideal point in this paper. Since the multi-source of evaluation information is considered in the LINMAP model, the influence of information source weight and index weight on distance value is included at the same time. Let $D_{u}\left(D_{v}\right)$ be the distance between the evaluation value of the alternative $F_{u}\left(F_{v}\right)$ and its positive ideal point respectively. Using Eqs. (11) (13), $D_{u}$ and $D_{v}$ can be expressed as follows:

$$
\begin{aligned}
& D_{u}=\sum_{t=1}^{q} \sum_{j=1}^{n} s^{t} \omega_{u}^{t}\left(z_{u j}^{t}-z_{u j}^{t+}\right)^{2} \\
& D_{v}=\sum_{t=1}^{q} \sum_{j=1}^{n} s^{t} \omega_{v}^{t}\left(z_{v j}^{t}-z_{v j}^{t+}\right)^{2}
\end{aligned}
$$

If $D_{v}>D_{u}$, it means that the alternative $F_{u}$ is closer to the ideal point than the alternative $F_{v}$, that is, the alternative $F_{u}$ is superior to the alternative $F_{v}$; If $D_{v}<D_{u}$, it means that the alternative $F_{u}$ is further away 
from the ideal point than the alternative $F_{v}$, that is, the alternative $F_{u}$ is inferior to the alternative $F_{v}$. Therefore, the ranking order of the alternative $F_{u}$ and the alternative $F_{v}$ is determined by the preferences of all decision makers.

Let $\left(D_{u}-D_{v}\right)^{-}$and $\left(D_{u}-D_{v}\right)^{+}$denote the inconsistency and consistency between the alternative $F_{u}$ and the alternative $F_{v}$ respectively. Let $I C$ and $C$ denote the overall inconsistency and overall consistency respectively. When $D_{u}<D_{v}$, the value of $\left(D_{u}-D_{v}\right)^{-}$is $D_{v}-D_{u}$; When $D_{u} \geq D_{v}$, the value of $\left(D_{u}-D_{v}\right)^{-}$is zero. The inconsistency can be written as follows:

$$
\left(D_{u}-D_{v}\right)^{-}= \begin{cases}D_{v}-D_{u} & \left(D_{u}<D_{v}\right) \\ 0 & \left(D_{u} \geq D_{v}\right)\end{cases}
$$

The inconsistency $\left(D_{u}-D_{v}\right)^{-}$can be rewritten as follows:

$$
\left(D_{u}-D_{v}\right)^{-}=\max \left\{0, D_{v}-D_{u}\right\}
$$

Considering the overall preferences of all experts, the total inconsistency can be expressed as follows:

$$
I C=\sum_{(u, v) \in \Omega}\left(D_{u}-D_{v}\right)^{-}=\sum_{(u, v) \in \Omega} \max \left\{0, D_{v}-D_{u}\right\}
$$

Similarly, the consistency $\left(D_{u}-D_{v}\right)^{+}$can be expressed as follows:

$$
\left(D_{u}-D_{v}\right)^{+}= \begin{cases}D_{u}-D_{v} & \left(D_{u} \geq D_{v}\right) \\ 0 & \left(D_{u}<D_{v}\right)\end{cases}
$$

The consistency $\left(D_{u}-D_{v}\right)^{+}$can be rewritten as follows:

$$
\left(D_{u}-D_{v}\right)^{+}=\max \left\{0, D_{u}-D_{v}\right\}
$$

Considering the overall preferences of all experts, the total inconsistency can be expressed as follows:

$$
C=\sum_{(u, v) \in \Omega}\left(D_{u}-D_{v}\right)^{+}=\sum_{(u, v) \in \Omega} \max \left\{0, D_{u}-D_{v}\right\}
$$

For the pair $(u, v) \in \Omega$, there exists $\lambda_{u v} \geq 0$. Let $\lambda_{u v}=\max \left\{0, D_{v}-D_{u}\right\}$, there is as follows:

$$
\lambda_{u v} \geq D_{v}-D_{u}
$$

Referring to the PPSQ evaluation practice and related theoretical researches, the preference values of information source weight and index weight are determined in advance according to the preferences of property management experts and the literatures (Yu et al. 2018; Wan et al. 2020). The preference sets of information source weight and index weight by all experts are denoted as $H_{1}$ and $H_{2}$ respectively. Therefore, the multi-objective LINMAP model can be expressed as follows: 


$$
\begin{aligned}
& \min \{I C\}=\sum_{(u, v) \in \Omega} \lambda_{u v} \\
& \min \{E\}=\sum_{i=1}^{m} \sqrt{\frac{1}{q} \sum_{t=1}^{q}\left(z_{i}^{t}-\sum_{t=1}^{q}\left(s^{t} \sum_{j=1}^{n} \omega_{j}^{t} z_{i j}^{t}\right)\right)^{2}} \\
& \left\{\begin{array}{l}
\sum_{(u, v) \in \Omega} \sum_{t=1}^{q} \sum_{i=1}^{m} \sum_{j=1}^{n} s^{t} \omega_{i}^{t}\left[\left(z_{v j}^{t 2}-z_{u j}^{t 2}\right)+2 z_{i j}^{t+}\left(z_{u j}^{t}-z_{v j}^{t}\right)\right] \geq h \\
\sum_{t=1}^{q} \sum_{i=1}^{m} \sum_{j=1}^{n} s^{t} \omega_{i}^{t}\left[\left(z_{u j}^{t}{ }^{2}-z_{v j}^{t}{ }^{2}\right)+2 z_{i j}^{t+}\left(z_{v j}^{t}-z_{u j}^{t}\right)\right]+\lambda_{u v} \geq 0 \\
s^{t} \in H_{1}, \sum_{t=1}^{q} s^{t}=1, s^{t}>0 \\
\omega_{i}^{t} \in H_{2}, \sum_{i=1}^{m} \omega_{i}^{t}=1, \omega_{i}^{t}>0 \\
\lambda_{u v}>0 \quad((u, v) \in \Omega)
\end{array}\right.
\end{aligned}
$$

where $h$ be the parameter given in advance, $\lambda_{u v}$ be the minimum inconsistency, and $h>0$ denotes the consistency greater than the inconsistency.

Since Eq. (23) is a multi-objective programming model. The parameter $r \in[0,1]$ is introduced in this paper. Two objective functions, the minimum of total inconsistency and the minimum sum of the standard deviation of the comprehensive evaluation value, are transformed into a single objective function. When $r=0$ or $r=1$, Eq. (23) is transformed into a single objective programming model; When $r=0.5$, the minimum overall inconsistency and the minimum sum of the standard deviation of the comprehensive evaluation value are equally important in Eq. (23). Therefore, Eq. (23) can be rewritten as follows:

$$
\begin{aligned}
& \min \left\{r \sum_{(u, v) \in \Omega} \lambda_{u v}+(1-r) \sum_{i=1}^{m} \sqrt{\left.\frac{1}{q} \sum_{t=1}^{q}\left(z_{i}^{t}-\sum_{t=1}^{q} \mid s^{t} \sum_{j=1}^{n} \omega_{j}^{t} z_{i j}^{t}\right)^{\prime}\right)^{2}}\right\} \\
& \left\{\begin{array}{l}
\sum_{(u, v) \in \Omega} \sum_{t=1}^{q} \sum_{i=1}^{m} \sum_{j=1}^{n} s^{t} \omega_{i}^{t}\left[\left(z_{v j}^{t 2}-z_{u j}^{t 2}\right)+2 z_{i j}^{t+}\left(z_{u j}^{t}-z_{v j}^{t}\right)\right] \geq h \\
\sum_{t=1}^{q} \sum_{i=1}^{m} \sum_{j=1}^{n} s^{t} \omega_{i}^{t}\left[\left(z_{u j}^{t}-z_{v j}^{t 2}\right)+2 z_{i j}^{t+}\left(z_{v j}^{t}-z_{u j}^{t}\right)\right]+\lambda_{u v} \geq 0 \\
s^{t} \in H_{1}, \sum_{t=1}^{q} s^{t}=1, s^{t}>0 \\
\omega_{i}^{t} \in H_{2}, \sum_{i=1}^{m} \omega_{i}^{t}=1, \omega_{i}^{t}>0 \\
\lambda_{u v}>0 \quad((u, v) \in \Omega) \\
r \geq 0, r \leq 1
\end{array}\right.
\end{aligned}
$$

\subsection{The basic steps of multi-objective LINMAP model}

In summary, the basic steps of LINMAP method based on multi-source information fusion are summarized as follows.

Step 1 Collect evaluation data from different information sources such as on-site visitors, netizens, supervisors and experts by questionnaire survey, web crawler, supervision records and expert evaluation.

Step 2 Eqs. (3) to (9) are respectively used to standardize processing for multi-source heterogeneous 
data based on the principle of Eq. (2).

Step 3 Collect experts' preference data on information source weight and index weight, and determine the restriction conditions of weight value according to the existing methods (Yu et al. 2018; Wan et al. 2020).

Step 4 Determine the positive ideal point of the standardized decision matrix based on multi-source heterogeneous information according to Eq. (14) or (15);

Step 5 Collect the total preference information of experts for pairwise comparison of different alternatives, and determine the total preference set $\Omega$;

Step 6 Determine the inconsistency and the consistency, and construct the LINMAP model based on multi-source heterogeneous information according to Eq. (24).

Step 7 Determine the threshold value $h$ and $r$, the final information source weight and index weight based on the sensitivity analysis results, relevant research results and expert experiences;

Step 8 Calculate the comprehensive distance of each alternative according to Eq. (14) or (15), and ranking order of all alternatives.

\section{Case analysis of PPSQ evaluation for public Building}

\subsection{Preprocessing of basic information}

The object of this study is the property service project of four adjacent public buildings in the same area of Wenzhou, China. These projects include museum $\left(A_{1}\right)$, library $\left(A_{2}\right)$, science $\&$ technology museum $\left(A_{3}\right)$ and grand theater $\left(A_{4}\right)$. Property services for most projects are provided by Wenzhou Sapphire Property Management Co., Ltd. (hereinafter referred to as Sapphire). In order to meet the requirements of the transformation and upgrading of the property service industry, Sapphire needs to develop a PPSQ evaluation method for public building. PPSQ based on multi-source heterogeneous information is evaluated by multi-objective LINMAP method. The evaluation indexes are divided into customer service $\left(C_{1}\right)$, cleaning $\left(C_{2}\right)$, safety $\left(C_{3}\right)$, greening $\left(C_{4}\right)$ and facilities $\left(C_{5}\right)$ according to the practice of property service industry and related theoretical research (Zuo et al. 2020; Zuo et al. 2021).

The evaluation subjects are on-site visitors, netizens, supervisors and experts. The method in Section 3.2 is used to collect basic evaluation information, the information collection methods of three information sources are illustrated here. According to the actual situation of property service industry and the advice of experts, the supervision records are determined as follows: the evaluation information of customer service is collected by expert opinion method, and the opinions of three invited experts are expressed in the form of triangular fuzzy number; the evaluation information of cleaning is come from average value of supervisors' daily evaluation; the evaluation information of safety is collected by uncertain number of supervisors, and the opinions of supervisors are expressed in the form of hesitant fuzzy number; the evaluation information of greening is come from department manager, and the opinions of the department manager are expressed in the form of language value; the evaluation information of facilities is come from engineer, and the opinions of engineer are expressed in the form of interval value. Based on the method in section 3.2, the online reviews is 
determined as follows: By analyzing any 50 online reviews related to the evaluation objects, a summary of online information lexicon of PPSQ evaluation for public building is shown in Table 2.

Table 2 Online review information lexicon of PPSQ evaluation

\begin{tabular}{|c|c|c|c|}
\hline $\begin{array}{c}\text { degree } \\
\text { adverbs }\end{array}$ & lexicon & $\begin{array}{c}\text { Emotion } \\
\text { words }\end{array}$ & lexicon \\
\hline $\mathrm{S}$ & $\begin{array}{l}\text { absolutely, altogether, completely, entirely, extremely, } \\
\text { fully, perfectly, quite, thoroughly, totally, utterly, wholly, } \\
\text { badly, bitterly, deeply, enormously, far, greatly, heartily, } \\
\text { highly, how, immensely, intensely, largely, particularly, } \\
\text { profoundly, tremendously, severely, strongly, terribly, } \\
\text { so, vastly, violently, well }\end{array}$ & $\mathrm{P}$ & $\begin{array}{l}\text { helpful, good, comfortable, strong, like, } \\
\text { convenient, gorgeous, great, exquisite, } \\
\text { atmospheric, excellent, high-end, clean, } \\
\text { neat, beautiful, complete, desirable, } \\
\text { modern, elegant, brilliant, friendly }\end{array}$ \\
\hline W & $\begin{array}{l}\text { but, just, merely, mildly, moderately, only, partially, } \\
\text { partly, quite, rather, simply, somewhat, slightly, a little, } \\
\text { little, a bit, barely, hardly, scarcely, at all, in the least, in } \\
\text { the slightest, almost, nearly, practically, virtually }\end{array}$ & $\mathrm{N}$ & $\begin{array}{l}\text { ordinary, tolerable, ok, almost, rubbish, } \\
\text { bad, bad comment, make a mistake, } \\
\text { poor, cost, slow, annoying, puzzling }\end{array}$ \\
\hline
\end{tabular}

Notes: The above lexicon is from Chinese research samples. According to different research situations, the contents of lexicon can be appropriately added, modified and deleted.

Then, the method by combining web crawler and manual processing is used to collect the comment information of all evaluation objects on multiple network platforms in 2020, and online reviews of all evaluation objects are obtained. Since questionnaire survey is a mature method, it will not be repeated here. Using the above methods, the PPSQ evaluation data of four public buildings in 2020 are summarized as shown in Table 3.

Table 3 Basic evaluation data of PPSQ

\begin{tabular}{|c|c|c|c|c|c|c|c|c|c|c|c|c|c|c|c|c|c|c|c|c|c|c|c|c|c|}
\hline $\begin{array}{c}\text { Supervision } \\
\text { record }\end{array}$ & \multicolumn{5}{|c|}{$C_{1}^{1}$} & & & $C_{2}^{1}$ & & & \multicolumn{5}{|c|}{$C_{3}^{1}$} & & & $C_{4}^{1}$ & & & \multicolumn{5}{|c|}{$C_{5}^{1}$} \\
\hline$A_{1}$ & \multicolumn{5}{|c|}{$(3,4,5)$} & & & 90.94 & & & \multicolumn{5}{|c|}{$3,4,6$} & & & s5 & & & \multicolumn{5}{|c|}{$[7,9]$} \\
\hline$A_{2}$ & \multicolumn{5}{|c|}{$(2,3,4)$} & & & 35.21 & & & \multicolumn{5}{|c|}{$2,3,4$} & & & s4 & & & \multicolumn{5}{|c|}{$[6,7]$} \\
\hline$A_{3}$ & \multicolumn{5}{|c|}{$(1,2,3)$} & & & 33.52 & & & \multicolumn{5}{|c|}{$2,3,4,5$} & & & s3 & & & \multicolumn{5}{|c|}{$[5,7]$} \\
\hline$A_{4}$ & \multicolumn{5}{|c|}{$(4,5,7)$} & & & 4.35 & & & \multicolumn{5}{|c|}{$6,6,7,8$} & & & s4 & & & \multicolumn{5}{|c|}{$[8,9]$} \\
\hline $\begin{array}{c}\text { Online } \\
\text { reviews }\end{array}$ & \multicolumn{5}{|c|}{$C_{1}^{2}$} & & & $C_{2}^{2}$ & & & \multicolumn{5}{|c|}{$C_{3}^{2}$} & \multicolumn{5}{|c|}{$C_{4}^{2}$} & \multicolumn{5}{|c|}{$C_{5}^{2}$} \\
\hline$S^{2}$ & \multicolumn{2}{|c|}{1} & 2 & \multicolumn{2}{|c|}{3} & \multicolumn{2}{|l|}{1} & 2 & 3 & 3 & \multicolumn{2}{|c|}{1} & 2 & \multicolumn{2}{|r|}{3} & \multicolumn{2}{|l|}{1} & 2 & & 3 & \multicolumn{2}{|l|}{1} & 2 & & 3 \\
\hline$A_{1}$ & 41 & & 54 & & 16 & 42 & & 46 & 2 & 5 & 68 & & 92 & & 56 & 47 & & 54 & & 18 & 78 & & 130 & & 36 \\
\hline$A_{2}$ & 52 & & 37 & & 16 & 59 & & 36 & 2 & 4 & 108 & & 84 & & 36 & 47 & & 45 & & 17 & 108 & & 96 & & 38 \\
\hline$A_{3}$ & 42 & & 42 & & 13 & 58 & & 33 & 1 & 6 & 90 & & 94 & & 32 & 59 & & 38 & & 12 & 116 & & 78 & & 56 \\
\hline$A_{4}$ & 28 & & 64 & & 18 & 41 & & 41 & 2 & 8 & 50 & & 122 & & 58 & 38 & & 51 & & 29 & 62 & & 114 & & 62 \\
\hline $\begin{array}{c}\text { Questionnaire } \\
\text { survey }\end{array}$ & & & $C_{1}^{3}$ & & & & & $C_{2}^{3}$ & & & & & $C_{3}^{3}$ & & & & & $C_{4}^{3}$ & & & & & $C_{5}^{3}$ & & \\
\hline$S^{3}$ & 1 & 2 & 3 & 4 & 5 & 1 & 2 & 3 & 4 & 5 & 1 & 2 & 3 & 4 & 5 & 1 & 2 & 3 & 4 & 5 & 1 & 2 & 3 & 4 & 5 \\
\hline$A_{1}$ & 3 & 38 & 49 & 12 & 2 & 5 & 35 & 45 & 18 & 1 & 5 & 33 & 42 & 22 & 2 & 7 & 38 & 46 & 12 & 1 & 2 & 31 & 58 & 11 & 2 \\
\hline$A_{2}$ & 12 & 51 & 32 & 7 & 2 & 5 & 50 & 38 & 8 & 3 & 7 & 49 & 38 & 9 & 1 & 10 & 48 & 36 & 9 & 1 & 4 & 48 & 43 & 9 & 0 \\
\hline$A_{3}$ & 20 & 40 & 37 & 6 & 1 & 15 & 50 & 31 & 7 & 1 & 15 & 38 & 42 & 7 & 2 & 13 & 49 & 35 & 6 & 1 & 12 & 45 & 33 & 12 & 2 \\
\hline$A_{4}$ & 7 & 25 & 59 & 12 & 1 & 6 & 37 & 39 & 20 & 2 & 7 & 19 & 56 & 20 & 2 & 6 & 28 & 46 & 22 & 2 & 9 & 22 & 49 & 19 & 5 \\
\hline
\end{tabular}

According to the principle of Eq. (2), Eqs. (3) (9) are respectively used to standardize the basic data, 
and the results are shown in Table 4.

Table 4 Standardized evaluation data of PPSQ

\begin{tabular}{cccccc}
\hline Supervision record & $\omega_{1}^{1}$ & $\omega_{2}^{1}$ & $\omega_{3}^{1}$ & $\omega_{4}^{1}$ & $\omega_{5}^{1}$ \\
\hline$A_{1}$ & 0.353 & 1.000 & 1.000 & 1.000 & 0.615 \\
$A_{2}$ & 0.000 & 0.000 & 0.035 & 0.000 & 0.000 \\
$A_{3}$ & 0.088 & 0.033 & 0.000 & 0.250 & 0.077 \\
$A_{4}$ & 1.000 & 1.000 & 1.000 & 1.000 & 1.000 \\
\hline Online reviews & $\omega_{1}^{2}$ & $\omega_{2}^{2}$ & $\omega_{3}^{2}$ & $\omega_{4}^{2}$ & 0.266 \\
\hline$A_{1}$ & 0.506 & 1.000 & 0.239 & 0.460 & 0.000 \\
$A_{2}$ & 0.040 & 0.702 & 0.011 & 0.092 & 0.176 \\
$A_{3}$ & 0.000 & 0.000 & 0.000 & 0.000 & 1.000 \\
$A_{4}$ & 1.000 & 0.895 & 1.000 & 1.000 & $\omega_{5}^{3}$ \\
\hline$A_{1}$ & $\omega_{1}^{3}$ & $\omega_{2}^{3}$ & $\omega_{3}^{3}$ & 0.299 & 0.617 \\
$A_{2}$ & 0.876 & 1.000 & 0.694 & 0.036 & 0.020 \\
$A_{3}$ & 0.029 & 0.295 & 0.011 & 0.000 & 0.000 \\
$A_{4}$ & 0.000 & 0.000 & 0.000 & 1.000 & 1.000 \\
\hline
\end{tabular}

In addition to the above sub-item evaluation information, property management experts from university, government and industry association are also invited to make overall evaluation of PPSQ of each project, and experts compare projects in pairs and evaluate them according to their preferences. The set of all experts' preference values is denoted as follows:

$$
\Omega_{R}=\{(1,2),(2,3),(1,4),(3,4)\}
$$

where $(1,2)$ indicates that the PPSQ of the project $A_{1}$ is not inferior to the project $A_{2}$. Other pairs can be explained in a similar way.

\subsection{Evaluation analysis process}

Because the evaluation values of each index in different information sources are all benefit variables. According to the data in Eq. (13) and Table 3, the positive ideal point of the LINMAP model is as follows:

$$
\left(z_{i j}^{t+}\right)_{n \times q}=(1.000)_{5 \times 3}
$$

Each expert is consulted on the range of changes in the information source weight. The opinions of each expert form a set, and the union of all sets is calculated. The result is as follows:

$$
H_{1}=\left\{\left(s^{1}, s^{2}, s^{3}\right) \mid s^{1} \geq 0.2 ; s^{2} \geq 0.2 ; s^{3}-s^{2} \geq s^{2}-s^{1}\right\}
$$

The weight value of the same index may be different in different information sources. Experts think that the relationship between the weights of different indexes is similar in different information sources, so there is a roughly similar relationship. According to the method in the literatures (Yu et al. 2018; Wan et al. 2020) and the opinions of experts, the weight relationship of all indexes can be expressed as follows: 


$$
\begin{aligned}
H_{2}= & \left\{\left(\omega_{1}^{t}, \omega_{2}^{t}, \omega_{3}^{t}, \omega_{4}^{t}, \omega_{5}^{t}\right) \mid 0.15 \leq \omega_{1}^{t} \leq 0.45 ; 0.1 \leq \omega_{2}^{t} \leq 0.2 ; 0.1 \leq \omega_{3}^{t} \leq 0.25 ; \omega_{4}^{t} \geq 0.12 ;\right. \\
& \left.\omega_{5}^{t} \geq 0.15 ; \omega_{1}^{t} \geq 1.3 \omega_{2}^{t} ; \omega_{2}^{t}-\omega_{3}^{t} \leq 0.05 ; \omega_{1}^{t}-\omega_{2}^{t} \geq \omega_{5}^{t}-\omega_{4}^{t} ; t=1,2,3\right\}
\end{aligned}
$$

Substitute the data in Eqs. (25) (28) and Table 3 into Eq. (24), and the multi-objective LINMAP model of PPSQ for public building based on multi-source heterogeneous information is shown in Eq. (29).

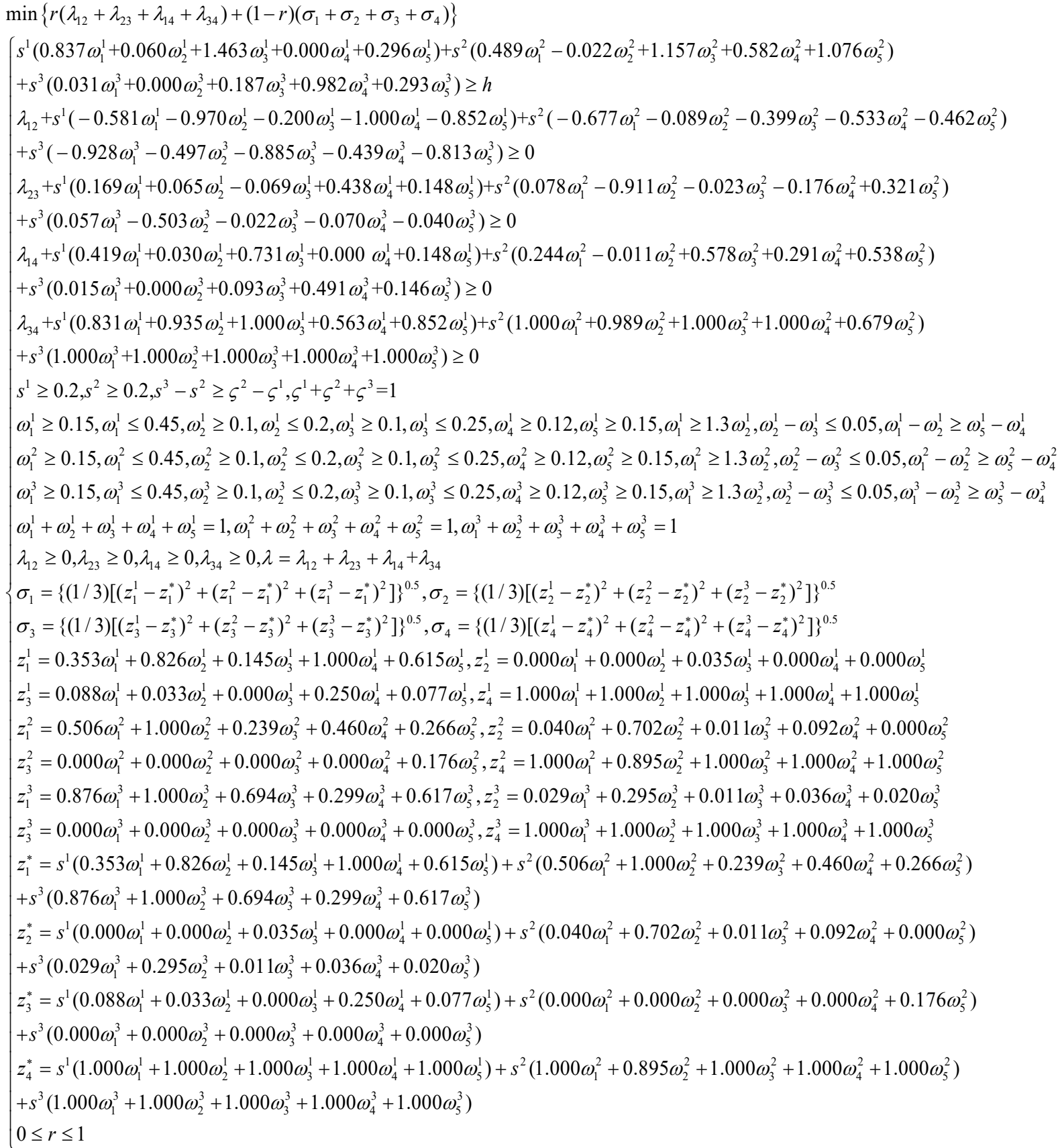

\subsection{Determination of evaluation results}

The values of $h$ and $r$ are determined by comprehensively considering existing researches, sensitivity analysis and expert experience. According to the principle of LINMAP, the value $h$ must be greater than or 
equal to zero. And because when $h \geq 0.8$, Eq. (29) has no feasible solution. Therefore, the range of the value $r$ is $[0,0.7]$. Since the new model contains two thresholds, the sensitivity analysis is performed alternately with the two thresholds.

Assume that $r=0.5$ is fixed. When 0.1 is taken as an interval and $h$ is taken different values, the calculated results of information source weight and index weight are summarized in Table 5. Obviously, when $h \in[0.0,0.7]$, the weights of all evaluation indexes and information sources remain stable.

Table 5 Sensitivity analysis I ( $r=0.5$ )

\begin{tabular}{cccccccccc}
\hline$h$ & 0.0 & 0.1 & 0.2 & 0.3 & 0.4 & 0.5 & 0.6 & 0.7 \\
\hline$s^{1}$ & 0.363 & 0.363 & 0.363 & 0.363 & 0.363 & 0.363 & 0.363 & 0.363 \\
$s^{2}$ & 0.437 & 0.437 & 0.437 & 0.437 & 0.437 & 0.437 & 0.437 & 0.437 \\
$s^{3}$ & 0.200 & 0.200 & 0.200 & 0.200 & 0.200 & 0.200 & 0.200 & 0.200 \\
$\omega_{1}^{1}$ & 0.380 & 0.380 & 0.380 & 0.380 & 0.380 & 0.380 & 0.380 & 0.380 \\
$\omega_{2}^{1}$ & 0.100 & 0.100 & 0.100 & 0.100 & 0.100 & 0.100 & 0.100 & 0.100 \\
$\omega_{3}^{1}$ & 0.250 & 0.250 & 0.250 & 0.250 & 0.250 & 0.250 & 0.250 & 0.250 \\
$\omega_{4}^{1}$ & 0.120 & 0.120 & 0.120 & 0.120 & 0.120 & 0.120 & 0.120 & 0.120 \\
$\omega_{5}^{1}$ & 0.150 & 0.150 & 0.150 & 0.150 & 0.150 & 0.150 & 0.150 & 0.150 \\
$\omega_{1}^{2}$ & 0.150 & 0.150 & 0.150 & 0.150 & 0.150 & 0.150 & 0.150 & 0.150 \\
$\omega_{2}^{2}$ & 0.100 & 0.100 & 0.100 & 0.100 & 0.100 & 0.100 & 0.100 & 0.100 \\
$\omega_{3}^{2}$ & 0.250 & 0.250 & 0.250 & 0.250 & 0.250 & 0.250 & 0.250 & 0.250 \\
$\omega_{4}^{2}$ & 0.225 & 0.225 & 0.225 & 0.225 & 0.225 & 0.225 & 0.225 & 0.225 \\
$\omega_{5}^{2}$ & 0.275 & 0.275 & 0.275 & 0.275 & 0.275 & 0.275 & 0.275 & 0.275 \\
$\omega_{1}^{3}$ & 0.150 & 0.150 & 0.150 & 0.150 & 0.150 & 0.150 & 0.150 & 0.150 \\
$\omega_{2}^{3}$ & 0.100 & 0.100 & 0.100 & 0.100 & 0.100 & 0.100 & 0.100 & 0.100 \\
$\omega_{3}^{3}$ & 0.100 & 0.100 & 0.100 & 0.100 & 0.100 & 0.100 & 0.100 & 0.100 \\
$\omega_{4}^{3}$ & 0.500 & 0.500 & 0.500 & 0.500 & 0.500 & 0.500 & 0.500 & 0.500 \\
$\omega_{5}^{3}$ & 0.150 & 0.150 & 0.150 & 0.150 & 0.150 & 0.150 & 0.150 & 0.150 \\
\hline
\end{tabular}

Similarly, assuming that $h=0.4$ is fixed and $r$ is taken different values based on the interval 0.1, the calculation results of information source weight and evaluation index weight are shown in Table 6 . When $r \in[0.2,1.0]$, the information sources weights and evaluation index do not change; When the value $r$ is close to 0 , the information source weight and evaluation index changes greatly. At this time, if sensitivity analysis is performed on the changed value $h$, the sensitivity analysis result is the same as that in Table 5 when the value $h$ is $[0.1,0.7]$. When the value of $r$ is close to 0 , the sensitivity analysis results are similar that of table 6 .

According to the above analysis, when $h$ and $r$ are the reasonable range of feasible solutions in Eq. (29), the weight of information source and evaluation index will change only when the two coefficients are respectively close to the upper and lower limits. When $h$ and $r$ are other values, the weights of information sources and evaluation indexes remain stable. Therefore, combined with the above sensitivity analysis results, existing research results (Wan and Li, 2013; Wan et al. 2020; Zuo et al. 2020; Zuo et al. 2021) and 
expert opinions, this paper determines $h=0.4$ and $h=0.5$. In this case, the calculation results of Eq. (29) are summarized in Table 7.

Table 6 Sensitivity analysis II $(h=0.4)$

\begin{tabular}{ccccccccccccc}
\hline$r$ & 0 & 0.1 & 0.2 & 0.3 & 0.4 & 0.5 & 0.6 & 0.7 & 0.8 & 0.9 & 1.0 \\
\hline$s^{1}$ & 0.384 & 0.354 & 0.363 & 0.363 & 0.363 & 0.363 & 0.363 & 0.363 & 0.363 & 0.363 & 0.363 \\
$s^{2}$ & 0.340 & 0.446 & 0.437 & 0.437 & 0.437 & 0.437 & 0.437 & 0.437 & 0.437 & 0.437 & 0.437 \\
$s^{3}$ & 0.276 & 0.200 & 0.200 & 0.200 & 0.200 & 0.200 & 0.200 & 0.200 & 0.200 & 0.200 & 0.200 \\
$\omega_{1}^{1}$ & 0.267 & 0.380 & 0.380 & 0.380 & 0.380 & 0.380 & 0.380 & 0.380 & 0.380 & 0.380 & 0.380 \\
$\omega_{2}^{1}$ & 0.200 & 0.100 & 0.100 & 0.100 & 0.100 & 0.100 & 0.100 & 0.100 & 0.100 & 0.100 & 0.100 \\
$\omega_{3}^{1}$ & 0.250 & 0.250 & 0.250 & 0.250 & 0.250 & 0.250 & 0.250 & 0.250 & 0.250 & 0.250 & 0.250 \\
$\omega_{4}^{1}$ & 0.120 & 0.120 & 0.120 & 0.120 & 0.120 & 0.120 & 0.120 & 0.120 & 0.120 & 0.120 & 0.120 \\
$\omega_{5}^{1}$ & 0.163 & 0.150 & 0.150 & 0.150 & 0.150 & 0.150 & 0.150 & 0.150 & 0.150 & 0.150 & 0.150 \\
$\omega_{1}^{2}$ & 0.450 & 0.150 & 0.150 & 0.150 & 0.150 & 0.150 & 0.150 & 0.150 & 0.150 & 0.150 & 0.150 \\
$\omega_{2}^{2}$ & 0.100 & 0.100 & 0.100 & 0.100 & 0.100 & 0.100 & 0.100 & 0.100 & 0.100 & 0.100 & 0.100 \\
$\omega_{3}^{2}$ & 0.100 & 0.209 & 0.250 & 0.250 & 0.250 & 0.250 & 0.250 & 0.250 & 0.250 & 0.250 & 0.250 \\
$\omega_{4}^{2}$ & 0.200 & 0.246 & 0.225 & 0.225 & 0.225 & 0.225 & 0.225 & 0.225 & 0.225 & 0.225 & 0.225 \\
$\omega_{5}^{2}$ & 0.150 & 0.296 & 0.275 & 0.275 & 0.275 & 0.275 & 0.275 & 0.275 & 0.275 & 0.275 & 0.275 \\
$\omega_{1}^{3}$ & 0.150 & 0.150 & 0.150 & 0.150 & 0.150 & 0.150 & 0.150 & 0.150 & 0.150 & 0.150 & 0.150 \\
$\omega_{2}^{3}$ & 0.100 & 0.100 & 0.100 & 0.100 & 0.100 & 0.100 & 0.100 & 0.100 & 0.100 & 0.100 & 0.100 \\
$\omega_{3}^{3}$ & 0.100 & 0.100 & 0.100 & 0.100 & 0.100 & 0.100 & 0.100 & 0.100 & 0.100 & 0.100 & 0.100 \\
$\omega_{4}^{3}$ & 0.500 & 0.500 & 0.500 & 0.500 & 0.500 & 0.500 & 0.500 & 0.500 & 0.500 & 0.500 & 0.500 \\
$\omega_{5}^{3}$ & 0.150 & 0.150 & 0.150 & 0.150 & 0.150 & 0.150 & 0.150 & 0.150 & 0.150 & 0.150 & 0.150 \\
\hline & & & & & & & & & & &
\end{tabular}

Table 7 Calculation results of information source weight and index weight ( $h=0.4, r=0.5$ )

\begin{tabular}{cccccccc}
\hline $\begin{array}{c}\text { Information } \\
\text { sources }\end{array}$ & Weight value & $\begin{array}{c}\text { Supervision } \\
\text { record }\end{array}$ & Weight value & Online review & Weight value & $\begin{array}{c}\text { Questionnaire } \\
\text { survey }\end{array}$ & Weight value \\
\hline$s^{1}$ & 0.363 & $\omega_{1}^{1}$ & 0.380 & $\omega_{1}^{2}$ & 0.150 & $\omega_{1}^{3}$ & 0.150 \\
$s^{2}$ & 0.437 & $\omega_{2}^{1}$ & 0.100 & $\omega_{2}^{2}$ & 0.100 & $\omega_{2}^{3}$ & 0.100 \\
$s^{3}$ & 0.200 & $\omega_{3}^{1}$ & 0.250 & $\omega_{3}^{2}$ & 0.250 & $\omega_{3}^{3}$ & 0.100 \\
& & $\omega_{4}^{1}$ & 0.120 & $\omega_{4}^{2}$ & 0.225 & $\omega_{4}^{3}$ & 0.500 \\
& & $\omega_{5}^{1}$ & 0.150 & $\omega_{5}^{2}$ & 0.275 & $\omega_{5}^{3}$ & 0.150 \\
\hline
\end{tabular}

Based on the weight values of three information sources and five evaluation indexes shown in Table 7 and the data in Table 3, the comprehensive value of each project is calculated by using Eq. (14). The results are as follows: $D_{1}=0.310, D_{2}=0.911, D_{3}=0.926, D_{4}=0.000$. Because the comprehensive value reflects the distance between each alternative and its positive ideal point. Therefore, the ranking order of PPSQ of four projects is as follows:

$$
A_{4} \succ A_{1} \succ A_{2} \succ A_{3}
$$

\section{Analysis of evaluation results}

The above data analysis results mainly include information source weight, evaluation index weight and comprehensive ranking order. Using the above three sets of data, the PPSQ evaluation results of public buildings based on multi-source heterogeneous information are analyzed respectively as follows: 
(1) In terms of information source weight results, the information source weight of online review is the highest, followed by the supervision record information source, and the questionnaire survey information source weight is the lowest. According to the different functions of property service enterprise, the supervision records are expressed in different data types, reflecting the professional opinions of the functional departments of property service enterprises. Online review reflects netizens' opinions in all network platforms, while questionnaire survey reflects the direct evaluation opinions of on-site visitors. The difference is that the former shows that the impact of online review on PPSQ evaluation is bigger, while the latter shows that the impact of traditional questionnaire survey on PPSQ evaluation is smaller. The similarity is that both reflect the feelings of visitors. In addition, the weight of information source can also be used as the basis for data source selection. If the weight of an information source is less than 0.1 , the data of this information source should be removed from the similar PPSQ evaluation in the future.

(2) In terms of evaluation index weight results, the weight values of some evaluation index have changed greatly in different information sources. As for the supervision records information source, the impact of each index on the PPSQ of public building from the largest to the smallest is customer service, safety, facilities, greening and cleaning. As for the online review information source, the impact of each index on the PPSQ of public building from the largest to the smallest is facilities, safety, cleaning, greening, customer service and cleaning. As for the questionnaire survey information source, the impact of each index on the PPSQ of public building from large to small is greening, customer service, facilities, safety and cleaning. It can be seen that there is a great difference in the ranking order of the evaluation indexes of the three information sources. However, there are some basic rules. For instance, the facilities weight is higher in all information sources, while the cleaning weight is lower in all information sources.

(3) In terms of final ranking order results, the PPSQ of public building from high to low is grand theater, museum, library and science \& technology museum. The comprehensive values are calculated respectively according to three different information sources, and the ranking orders are the same as above. It can be seen that the comprehensive value of professional opinion and visitor opinion has a good consistency. The results of data analysis not only objectively reflect the status quo of the service quality of the four property service projects, but also reveal the reasons for the difference of PPSQ. According to the field research and expert opinions, the visitor flow of grand theater and museum is relatively stable, 
the visiting order is good, and the pressure on property service is low. However, libraries and science \& technology museum have large numbers of children visitors, the flow of people is large, the environment is relatively noisy, and the pressure on property service is high. Therefore, the difference in the characteristics of property service projects is the main reason of the difference in PPSQ for public buildings.

\section{Conclusions}

In order to evaluate PPSQ for public buildings, this paper proposes a multi-objective LINMAP model and a PPSQ evaluation method based on multi-source heterogeneous information. The innovation of this research is reflected in the following two aspects:

(1) There is a high degree of heterogeneity between the two objectives in the multi-objective LINMAP model. The two objectives respectively represent the minimum inconsistency and the minimum difference of multi-source evaluation results, which improves the existing evaluation method.

(2) The proposed method takes into account various types of evaluation subject, multi-source heterogeneous evaluation information and large-scale data processing requirements. The comprehensive collection and effective integration of basic evaluation information are realized, and the evaluation level of PPSQ is improved.

In a word, the new PPSQ method enriches the method system of PPSQ evaluation, but also adapts to the requirements of modern property service quality evaluation.

In the follow-up research, on the one hand, the method innovation can be realized by improving other classical decision models based on the needs of different evaluation environments; on the other hand, the multi-objective LINMAP method can be applied to the quality evaluation in other fields such as product design, tourism service, library management, etc.

Funding This work was supported by the the National Statistical Science Research Project of China (No. 2021LY100, 2021LZ33), National Natural Science Foundation of China (No. 71972121) and National Social Science Foundation of China (No. 72001126).

\section{Declarations}

Conflict of interest The authors declare that there is no conflict of interests regarding the publication of this paper.

Ethical approval This paper does not contain any studies with human participants or animals performed by any of the authors.

Informed consent Informed consent was obtained from all individual participants included in the research.

Authorship contributions Wenjin Zuo: Conceptualization, Methodology, Formal analysis, Writing-original draft. Lijun Liu: Investigation, Methodology. Xiaogang He: Conceptualization, Project administration. Xingxian Zhang: Conceptualization, Methodology. Shouzhen Zeng: Conceptualization, Supervision. 


\section{References}

Bazeer Ahamed B, Murugan K (2020) Study of socio-linguistics online review system using sentiment scoring method. Int Conf Intell Comput Opt, 1072. Springer, Cham.

Berry LL, Parasuraman A, Zeithaml VA (1988) The service-quality puzzle. Bus Horizons, 31(5):35-43.

Bruzgiene R, Narbutaite L, Adomkus T, Cibulskis R (2013) Subjective and objective MOS evaluation of user's perceived quality assessment for IPTV service: a study of the experimental investigations. Elektron Elektrotech 19(7):110-113.

Gronroos C (1983) Strategic management and marketing in the service sector. Cambridge. Mass: Marketing Science Institute, 83-104.

Hung CJ, Chang HH, Eng CJ, Wong KH (2013) Service quality and perceived value of technology-based service encounters: evaluation of clinical staff satisfaction in Taiwan. Health Inf Manag J 42(1):29-36.

Jomnonkwao S, Ratanavaraha V (2016) Measurement modelling of the perceived service quality of a sightseeing bus service: an application of hierarchical confirmatory factor analysis. Transp Policy 45:240-252.

Kao TW, Lin WT (2016) The relationship between perceived e-service quality and brand equity: a simultaneous equations system approach. Comput Hum Behav 57:208-218.

Knecht-Tarczewska M (2013) Adjustment of the perceived service quality measurement methods in the evaluation of marketing offer of shopping centers. Nucl Technol Radiat Prot 28(2):163-168.

Lee K, Yu CY (2018) Assessment of airport service quality: a complementary approach to measure perceived service quality based on google reviews. J Air Transp Manag 71:28-44.

Liao HC, Jiang LS, Xu ZS, Xu J P, Herrera F (2017) A linear programming method for multiple criteria decision making with probabilistic linguistic information. Inf Sci 415:341-355.

Liao HC, Xu ZS, Zeng XJ (2014) Distance and similarity measures for hesitant fuzzy linguistic term sets and their application in multicriteria decision-making. Inf Sci 271:125-142.

Liu LJ, Zuo WJ (2019) Interval value weighted Muirhead mean operator and its application in perceived service quality evaluation. J Ind Tech Econ 38 (5):38-44.

Miranda S, Tavares P, Queiró R (2017) Perceived service quality and customer satisfaction: a fuzzy set QCA approach in the railway sector. J Bus Res 89:371-377.

Mudambi SM, Schuff D (2010) What makes a helpful online review? a study of customer reviews on amazon.com. MIS Q 34(1):185-200.

Qin JD, Liu XW, Pedrycz W (2017) A multiple attribute interval type-2 fuzzy group decision making and its application to supplier selection with extended LINMAP method. Soft Comput 21(12):3207-3226.

Ramanathan R, Karpuzcu H (2011) Comparing perceived and expected service using an AHP model: an application to measure service quality of a company engaged in pharmaceutical distribution. Opsearch 48(2):136-152.

Srinivasan V, Shocker AD (1973) Linear programming techniques for multidimensional analysis of preferences. Psychometrika 38:337-369.

Wan SP, Li DF (2013) Fuzzy LINMAP approach to heterogeneous MADM considering comparisons of alternatives with hesitation degrees. Omega 41:925-940.

Wan SP, Qin YL, Dong JY (2017) A hesitant fuzzy mathematical programming method for hybrid multi-criteria group decision making with hesitant fuzzy truth degrees. Knowl-Based Syst 138:232-248.

Wan SP, Zou WC, Dong JY (2020) Prospect theory based method for heterogeneous group decision making with hybrid truth degrees of alternative comparisons. Comput Ind Eng 141(3):106285.1-106285.14.

Wang C, Chen G, Wei Q (2018) A temporal consistency method for online review ranking. Knowl-Based Syst 143(1):259-270.

Wei ZC, Ma Q, Luo SR (2009) Study on interactive development of foreign large-scale public buildings and cities and its implications. U P Intl 23(1):92-96. 
Wu CH, Yuan YH, Tsai SB (2020) Using the DEMATEL model to expose core causal items of LibQUAL for improving library service quality: from the perspective of big data. Soft Comput 24(1):5729-5739.

Xie LL, Yang Y (2012) Studies of influence powers of participants in public project. S T Prog Pol 29(18):21-25.

Xu HY, Dong K, Wei L, Wang C, Yue ZH (2018) Research on multi-source data fusion method in scientometrics. J China Soc S T Info 37(3):318-328.

Yucesan M, Gul M (2020) Hospital service quality evaluation: an integrated model based on Pythagorean fuzzy AHP and fuzzy TOPSIS. Soft Comput 24(5):3237-3255.

Yu GF, Li DF, Fei W (2018) A novel method for heterogeneous multi-attribute group decision making with preference deviation. Comput Ind Eng 124:58-64.

Zhang R (2018) Between addition and subtraction: social impact of network information consumption. Theory M 32(6):180-188.

Zhang X, Fan ZP (2010) A method for large group decision making with multi-attribute and multi-identifier based on stochastic dominance rules. Syst Eng 28 (2):24-29.

Zuo WJ, Li DF, Yu GF, Zhang LP (2019) A large group decision-making method and its application to the evaluation of property perceived service quality. J Intell Fuzzy Syst 37(1):1513-1527.

Zuo WJ, Li DF, Yu GF (2020) A general multi-attribute multi-scale decision making method based on dynamic LINMAP for property perceived service quality evaluation. Technol Econ Dev Econ 26 (5):1052-1073.

Zuo WJ, Zhang XX, Zeng SZ, Liu LJ (2021) A LINMAP method based on the bounded rationality of evaluators for property service quality evaluation. IEEE Access. (in press). 